\title{
Transportation of steam-water mixture during development of steam-water fields.
}

\author{
Alexander Shulyupin ${ }^{1}$ and Natalia Varlamova $^{1^{*}}$ \\ ${ }^{1}$ Mining Institute of Far eastern branch of Russian Academy of Sciences, Khabarovsk, Russia.
}

\begin{abstract}
Annotation. The main problems of transporting the steam-water mixture revealed during steam-water fields development: pulsations of parameters at low flow rates and considerable hydraulic resistance at high flow rates. The domestic experience of the calculation of steam-water mixture pipelines, oriented to the dispersed-ring flow, is considered. Based on the analysis of domestic and foreign experience in the steam-water fields development, new challenges have been identified that make it urgent to develop scientific principles for the transport of steam-water mixture at low rates, taking into account modern concepts of the stability of steamwater flows.
\end{abstract}

\section{Introduction}

It is impossible to imagine modern life without the fuel and energy complex. Lighting, heating, heating food, water supply - almost any sphere of activity is carried out by energy consumption. For many regions where fuel is imported, as well as in view of the search for environmentally friendly solutions for energy production in the world as a whole, the question of using alternative energy sources, which include geothermal resources, is relevant. Geothermal energy is considered to be renewable, does not depend on weather conditions, it is not a source of carbon dioxide emissions into the atmosphere, and is available around the clock.

More than 80 countries use geothermal resources as a direct source of heat in heat pumps, balneological basins, heating systems, etc. [1]. More than 20 countries produce electricity from geothermal sources. [2]. In such countries as Costa Rica, El Salvador, Iceland, Kenya, the Philippines, the share of geothermal energy is $15-22 \%$ of the total electricity production. In future, this method is considered to be possible to produce about $8.3 \%$ of the total world electricity, which allows to meet the needs of $17 \%$ of the world population [3].

The greatest development of geothermal energy in Russia has received in the far East, where there are 5 geothermal electric power station (GEOENERGY). The source of heat carrier for this electric power station is the steam-water field, whose production wells bring to the surface a steam-water mixture. The largest field is Mutnovskaya (Kamchatka), which provides more than $80 \%$ of domestic electricity generation on geothermal resources. At the Mutnovsky field, the transportation of the heat carrier from the production wells to the geopower Station is carried out through the pipelines of the steam-water mixture [4]. This work

\footnotetext{
*Corresponding author: vnn-dvgups@mail.ru
} 
is devoted to problems of the specified type of transport of the heat carrier in the fields paramerters.

\section{Problems of transportation of steam-water mixture and their solutions}

At the beginning of development of steam-water fields widely used separate scheme of transporting heat transfer fluid separation was carried out near the mouth of wells, steam pipelines were delivered to the station, water was poured to the terrain. The tightening of environmental requirements and the widespread introduction of reflux to maintain reservoir pressure, have caused the need to transport not only steam, but also water to a common place of use. In such cases, it is advisable to transport the steam-water mixture in the form in which it is obtained from the wells, and the phase separation is carried out at a common separation station [5]. In this regard, at the end of the last century, the scheme of two-phase transportation began to be actively implemented [6-9]. Interest in two-phase transportation remained in the following years [10-13].

Operation of steam-water mixture pipelines revealed two major problems: the pulsations of flow parameters, typical for low flow rates, and a significant hydraulic resistance, which is characteristic for high flow rates. That's why, at the design stage of pipelines there was a problem of choosing the optimal diameter, which would provide minimal hydraulic losses and would provide a pulsation-free mode of transportation. Also there was a methodical problem - to perform the calculation of the pipeline in terms of the interrelation of pressure drop and flow, while taking into account the dependence of the flow rate of wells from wellhead pressure.

There is very little information in the world practice about the specific ways of solving these problems. Consider in more detail their decision in the development of domestic fields. A. N. Shulyupin and A. A. Chermoshentseva developed a computer program MODEL for calculation of steam-water mixture pipelines [4]. Initially, the program was conceived as a simplified version of a larger product based on a complex model of the dispersion-ring flow [14]. But the ease of use, and most importantly sufficient accuracy, identified in the course of emergency calculations, predetermined its widespread use.

The program involves the calculation of the pressure drop by the value of the parameters at one node point, that is applicable for short pipes. Long pipes should be divided into short design areas (up to $200 \mathrm{~m}$ ). The state parameters are calculated by the equations IAPWS-IF 97 [15]. The calculated recommendations are focused on the dispersion-ring flow. For the calculation section of the program determines the steam quantity according to the principle of the possibility of pulsation-free transportation under the condition

$$
x>\frac{1}{1+1,6 \sqrt{\rho^{\prime} / \rho^{\prime \prime}}},
$$

where $x$ - mass flow steam content; $\rho$ ' and $\rho "$ - density of water and steam.

Then a recommendation is issued on the choice of diameter for non-pulsation transportation according to the condition

$$
D \leq 0,252\left(\frac{4 G}{\pi \rho}\right)^{0,4},
$$

where $D$ is the inner diameter of the pipe; $G$ is the mass flow rate of the mixture; $\rho$ is the mixture density determined by the homogeneous model.

After entering the selected diameter, the pressure drop is calculated 


$$
\Delta p=\Delta p_{f}+\Delta p_{m},
$$

where $\Delta p$ - total pressure drop; $\Delta p_{f}-$ pressure drop due to friction; $\Delta p_{m}-$ total pressure drop in local resistances.

The differential pressure on friction is calculated by the formula obtained as a simplified generalization of the results of numerical implementation of the model of the dispersionring flow [14]

$$
\Delta p_{f}=\frac{0,02 \rho\left(v-v_{b}\right)^{2} L}{2 D}-
$$

where $\rho, v$ - the density and velocity of the mixture corresponding to the homogeneous model; $v_{b}-$ the velocity of the friction surface, equal to the critical velocity of the saturated water; $L$-the length of the design pipeline.

The pressure drop in local resistances are calculated according to the formula

$$
\Delta p_{m}=\frac{1,4 \rho v^{2}}{2},
$$

where $\zeta$ is the total coefficient of local resistance for a single-phase flow.

Usually, the pressure at the endpoint of the pipeline (at the inlet to the group station separator) is set as a constant parameter. The flow parameters of the mixture depend on the wellhead pressure. Practice has shown that to find a solution taking into account the influence of wellhead pressure is most convenient by graphic method, when the base of the well performance chart, reflecting the dependence of the flow rate of wellhead pressure, using the calculations of the pipeline to build a graph of the performance of the wellheadpipeline, reflecting the dependence of the flow rate on the pressure at the outlet of the pipeline [4]. Further steps are already being taken on the basis of this timetable.

With the use of the MODEL program, most of the existing pipelines at the Mutnovsky field were calculated [4], a lot of modifications of pipelines were reasonably made (replacement of U-shaped compensators with bellows, removal of non-functional shut-off valves, etc.), the calculation of two pipelines at the Pauzhet field was performed. In all cases, estimates of pressure drops and costs were confirmed.

In the work [11], 6 different variants of calculating the friction pressure drop are compared with experimental data obtained from the Lahendong geothermal field, Indonesia for horizontal pipes with a diameter of $10-22 "(0.254-0.559 \mathrm{~m})$. It is noted that in the experimental data the main one is the dispersion-ring flow regime. It is found that the homogeneous model gives one of the closest results to the experiments, especially for large diameter pipes. Note that the formula (4) is also close to the classical homogeneous model - only a correction for the velocity of the friction surface is introduced. The introduced correction (for the conditions of the Mutnovsky field $\mathrm{t}$ is about $6 \mathrm{~m} / \mathrm{s}$ ) reduces the calculated drop, but for large pipelines this reduction can be compensated by an increased value of the friction coefficient. In the formula (4), the coefficient of friction adopted 0.02. Unfortunately, in [11] there are no recommendations for determining the coefficient of friction, but indicates its dependence on the roughness. If it define the friction coefficient as a function of roughness, for pipes of small diameter it is most probably to be more than 0.02 , and for pipes of large diameter - less than 0.02 . Thus, it can be argued that the calculation of the considered recommendations is consistent not only with domestic experience, but also does not contradict the experimental data presented in [11].

\section{New challenges in transportation of steam-water mixture}

As noted, the low transport speeds of the mixture are associated with the risk of pulsations. In this regard, it is not recommended to combine the flows from different wells into one 
main pipeline - disconnection of one well can significantly reduce the flow rate and cause pulsations. However, the construction of individual pipelines from each well requires increased costs. Unsurprisingly that there are attempts to combine the flows from wells [11]. Note that the Mutnovsky field also has a similar experience. In this regard, the question of the scientific justification of such a decision, including the justification of the possibility of transportation with low flow rates, becomes relevant.

Transportation of the steam-water mixture under the condition (5) is associated with significant hydraulic losses. This raises the question about the possibility of liberalization of the conditions tailored to the specific circumstances. And the reasons for this are. For example, by designing a pipeline from a well 053 of $2240 \mathrm{~m}$ long, and given the absence of ascending sections, a diameter exceeding the limit (5) was deliberately chosen to reduce hydraulic losses. Subsequent exploitation confirmed the validity of this decision.

Experience shows that well over time reduces productivity. In a pipeline originally designed for a specific flow rate, the flow rate can fall over time to a value that does not meet the condition (5). The question of adjusting this condition arises again.

All of these points require a new approach to the definition of the conditions of nonpulsation transportation, which makes it possible to expand the calculation method in the area of lower flow rates. Note that the formula (4) is fundamentally oriented to high flow rates, i.e. a radical change in the calculation method is required.

A new view on the problem of stability of steam-water flows is proposed in [16]. It is shown that the stability of the operation mode of the well is directly related to the flow conditions in the system of ground transportation of the coolant. The condition of stable operation of the well is formulated as

$$
\frac{\partial \Delta p_{i n t}}{\partial G}+\frac{\partial p_{w}}{\partial G}>0
$$

where $\Delta p_{\text {int }}$ is the internal pressure drop in the well (or the sum of the pressure drops on friction, convective acceleration and gravity), $\Delta p_{w}$ is the wellhead pressure determined by the flow in the ground transportation system.

Since the wellhead pressure is the sum of the pressure at the outlet of the pipeline (in the group station separator) and the pressure drop in the ground pipeline, taking the outlet pressure constant, independent of the well flow, the condition (6) is written in the form

$$
\frac{\partial \Delta p_{i n t}}{\partial G}+\frac{\partial \Delta p_{t r}}{\partial G}>0
$$

where $\Delta p_{t r}$ is the pressure drop in the ground transportation system.

According to new ideas, the pipeline is a factor in stabilizing the operation of the well. With a spontaneous increase in the flow rate at the wellhead, the pressure drop in the pipeline increases, the wellhead pressure increases, the development of instability is extinguished. With a spontaneous decrease in the flow rate at the wellhead, the pressure drop in the pipeline is reduced, the wellhead pressure is reduced, causing a compensatory increase in the flow rate.

The new approach imposes even more stringent requirements for combining flows from different wells. The main pipeline is less dependent on the flow rate of one well, which reduces the second component of the left part (7), reducing the stability of the system. In this case, the stability of the system will be determined by the positive value of the first term. Moreover, a spontaneous disturbance, triggering the mechanism of instability can rely on a favorable for the development of instability disturbance in the main pipeline.

Special attention is paid to transportation at low flow rates, at which friction does not play a significant role. In the presence of upward sections, the pressure drop in the transportation system will be significantly dependent on the gravity component, which can 
decrease with increasing flow. In this case, the negative value of the second term of the left part (7) is possible, it means the pipeline will play a destabilizing role.

Thus, new challenges point to the relevance of the development of scientific foundations of transportation of steam-water mixture with low flow rates, taking into account modern ideas about the stability of steam-water flows. On the developed scientific basis, it is required to create a calculation method, which must necessarily take into account the gravitational component of the pressure drop in the pipeline.

\section{Conclusion}

1. Despite the rapid development of alternative energy sources, as well as of interest in many countries in this matter, today there is very limited information about the methods of calculation of two-phase transport systems of the coolant.

2. The existing methods of calculation of pipelines for the transportation of steam-water mixture are designed for high flow rates typical for the dispersion-ring mode.

3. Known methods of calculation are limited to taking into account hydraulic resistances due to friction and local resistances.

4. New challenges point to the need to develop a method of calculation of steam-water mixture pipelines for low flow rates, taking into account the gravitational component of the pressure drop.

The study was performed with financial support RFBR, research project No. 16-05-00398.

\section{References}

1. Lund, J.W., Boyd, T.L. Direct utilization of geothermal energy 2015 worldwide review. Geothermics 60, 66-93. (2016). doi:10.1016/j.geothermics.2015.11.004.

2. Bertani, R. Geothermal power generation in the world 2010-2014 update report. Geothermics 60, 31-43. (2016). doi:10.1016/j.geothermics.2015.11.003.

3. Bertani R. Geothermal energy: an overview on resources and potential // International Geothermal Days. - Slovakia, (2009).

4. SHulyupin A.N. Voprosy gidravliki parovodyanoj smesi pri osvoenii geotermal'nyh mestorozhdenij. - Vladivostok: Dal'nauka. 262 s. (2011).5. Earth sciences. - Paris: UNESCO, 12. (1973).

6. Lee K.C., Jenks D.G. Ohaaki geothermal steam transmission pipelines // Proceedings, 11-th New Zealand Geothermal Workshop. P. 25-30. (1989)

7. Wigly D.M. Separation plant and pipework design - Ohaaki steam field // Proceedings, 11-th New Zealand Geothermal Workshop.P. 19-24. (1989).

8. Delnov Y., Shulyupin A. Geothermal power generation in Kamchatka, Russia // Geothermal Resources Council Transactions. - Portland. 20. P. 733-736. (1996).

9. Zhao H.D., Lee K.C., Freeston D.H. Proceedings, World Geothermal Congress 2000. Kyushu-Tohoku. P. 3349-3353. (2000).

10. Ghaderi I. Comprehensive comparison between transmission two-phase flow in one line and two line separately for 50 MWe power plant in Sabalan, Iran. In: Proceedings of the World Geothermal Congress. Bali, Indonesia, no. 2501 (2010).

11. Rizaldy, S.J. Zarrouk. Pressure drop in large diameter geothermal two-phase pipelines // Proceedings 38th New Zealand Geothermal Workshop. - New Zealand. P. 1-5. (2016).

12. A. Garcia-Gutierrez, J.I. Martinez-Estrella, R. Ovando-Castelar, A. Vazquez-Sandoval, C. Rosales-López. Thermal Efficiency of the Los Humeros Geothermal Field Fluid Transportation Network. Proceedings World Geothermal Congress 2015 Melbourne, Australia, 19-25 April 2015, no. 25007. (2015). 
13. H.S. Cheik, H.A. Ali. Prefeasibility design of single flash in Asal geothermal power plant 2x25 MW, Djibouti. Proceedings World Geothermal Congress 2015 Melbourne, Australia, 19-25 April 2015, no. 25030. (2015).

14. SHulyupin A.N., CHermoshenceva A.A. Model' dispersno-kol'cevogo potoka v geotermal'noj skvazhine // Dinamika geterogennyh sred $\mathrm{v}$ geotekhnologicheskom proizvodstve. Petropavlovsk-Kamchatskij: Izd-vo KGARF. S. 23-35. (1998).

15. Aleksandrov A.A. Sistema uravnenij IFPWS-IF 97 dlya vychisleniya termodinamicheskih svojstv vody i vodyanogo para v promyshlennyh raschetah. CH. 1 . Osnovnye uravneniya // Teploehnergetika. № 9. S. 69-77. (1998).

16. Shulyupin, A.N. Steam-water flow instability in geothermal wells. International Journal of Heat and Mass Transfer 105, 290-295. (2017). doi:10.1016/j.ijheatmasstransfer.2016.09.092. 